\title{
The Situation of HIV/Mycobacterium tuberculosis Co-Infection in South America
}

\author{
Viviana Ritacco ${ }^{*}$, , Mariza Gonçalves Morgado ${ }^{2}$ and Luis Fernando García ${ }^{3}$ \\ ${ }^{I}$ National Council for Scientific Research (CONICET), Buenos Aires, Argentina \\ ${ }^{2}$ Oswaldo Cruz Foundation (FIOCRUZ): Rio de Janeiro CEP, Brazil \\ ${ }^{3}$ Grupo de Inmunología Celular e Inmunogenética (GICIG), Instituto de Investigaciones Médicas, Universidad de \\ Antioquia, Medellin, Colombia
}

\begin{abstract}
The work summarizes the results of a survey on human immunodeficiency virus (HIV) and Mycobacterium tuberculosis (MTB) situation that was undertaken within the frame of the EC FP7 EucoNet project. Updated data on HIV infection, acquired immunodeficiency syndrome (AIDS) and tuberculosis (TB) in South America are presented as well as a state of the art regarding disease management and research activities in 10 countries: Argentina, Brazil, Bolivia, Chile, Colombia, Ecuador, Paraguay, Peru, Uruguay and Venezuela. The average HIV prevalence is $0.5-<1.0 \%$ in most of the surveyed countries. Lower prevalences are found only in Bolivia, Chile and Ecuador. TB burden is unevenly distributed: Bolivia, Peru and Ecuador bear the highest disease loads (prevalence $>140 / 100,000$ ) whereas Chile, Uruguay and Venezuela bear the lowest (prevalence $<25 / 100,000$ ). HIV prevalence in incident TB cases ranges between $3 \%$ and $15 \%$ and mortality attributable to HIV/MTB co-infection is $<1 / 100,000$. All countries run national HIV/AIDS and TB control programmes with various degrees of efficiency and data availability/reliability. Diagnosis and treatment are free of charge and all countries adhere to diagnosis and treatment standards for TB and HIV/AIDS according to World Health Organisation guidelines. The main weaknesses are related to insufficient involvement of government administrations, poverty-related pockets of HIV/MTB co-infection in urban/suburban settings and lack of interaction between HIV/AIDS and TB programmes. Funds for HIV/AIDS are disproportionally higher than those allocated to TB and there is hardly any investment in the dual infection. Challenges and priority areas for research are presented, as stated by the South American experts at the EucoNet Workshop "Clinical and translational aspects of HIV/MTB co-infection" held in Stellenbosch, South Africa on July 23-24, 2009.
\end{abstract}

Keywords: Tuberculosis, drug resistance, AIDS, HIV, South America.

\section{INTRODUCTION}

Tuberculosis (TB) kills one third of people living with human immunodeficiency virus/acquired immunodeficiency syndrome (HIV/AIDS) worldwide. Reciprocally, one out of four TB deaths is related to HIV, a proportion that doubles previously acknowledged estimates. The dual epidemic is largely fuelled by the biological synergy that takes place between both pathogens, HIV and Mycobacterium tuberculosis (MTB), within the infected human hosts [1]. In particular, multidrug resistant (MDR) and extensively drug resistant (XDR) TB pose a grievous challenge to people living with HIV although there is scant knowledge on the magnitude and the mechanisms of such convergence [2]. The fact that MTB infection progresses more rapidly to TB disease in HIV infected people may lead to rapid development of an increasing pool of drug resistant TB patients in settings where MDR TB is prevalent [3].

South American countries have not been spared of the consequences of the association of these two deadly

\footnotetext{
*Address correspondence to this author at the Consejo Nacional de Investigaciones Científicas y Tecnológicas (CONICET), INEI ANLIS, Velez Sarsfield 563, 1281 Buenos Aires, Argentina;

Tel: +54 114302 7635; Fax: +54 114302 7635; E-mail:vritacco@anlis.gov.ar, vivianaritacco@gmail.com
}

pathogens. The present report describes the situation of HIV/AIDS and TB as well as the state of the art in management and research in South America according to the results of a survey undertaken within the framework of the FP7 EC EUCO-Net project. The report gathers updated epidemiological data on both diseases available from international and national sources together with information on ongoing scientific projects on HIV/AIDS and TB and available biomedical research funding from national and international organisations to South American institutions.

\section{SCOPE}

\section{Country Focus}

Country selection was based on: i) geopolitical, sociocultural, linguistic and scientific links with EUCO-Net coordinators and experts appointed beforehand, ii) accessibility to data and manpower, and iii) reliability of information. A total of 10 out of the 13 South American countries were included in the survey: Argentina, Bolivia, Brazil, Chile, Colombia, Ecuador, Paraguay, Peru, Uruguay and Venezuela. Other 3 countries are geographically located in South America but have separated historical, linguistic and cultural roots from those 10 and therefore were not included in this survey. The 3 countries that were let aside are Suriname, Guyana and French Guiana. Although these 
individual countries bear heavy HIV/AIDS loads, altogether contribute with less than $2 \%$ of the total population and joint AIDS/TB burden in South America.

\section{Timeframe and Data Sources}

At the time of conducting the survey, the most recent data freely accessible from global sources corresponded to 2007 and therefore this year was chosen for demographic and epidemiological analysis in the present report, unless stated otherwise. The main sources of information were assorted World Health Organisation (WHO) documents available on the internet and the national HIV/AIDS and TB programmes of individual countries. In particular, demographic data was mainly obtained from the WHO statistical information system [4]. Epidemiological data on HIV/AIDS was mainly based on the UNAIDS/WHO 2008 Report on the global AIDS epidemic [5] and the official reports of national HIV/AIDS programmes. Data on TB and MDR TB was obtained from the WHO Report on Tuberculosis 2009 [6] and the WHO Multidrug and extensively drug-resistant TB global report on surveillance and response [7]. National programmes provided, whenever available, additional information on disease diagnostics, management and on occurrence of MDR TB and XDR TB in particular countries.

\section{DEMOGRAPHIC ANALYSIS}

The combined population of the surveyed South American countries is 382 million. These 10 countries represent less than one third of the 35 countries comprised in the Latin American and Caribbean region but their merged population amounts to $68 \%$ of the total estimated population of such region, which makes up 560 million. Table 1 shows disaggregated demographic data, as adapted from the WHO statistical information system [4].

Overall, there is certain homogeneity in the demographic parameters of the surveyed countries, all with medium-low rates of income per capita and degrees of development. The median age is 28 ys $(0-14: 28 \% ; 15-64: 64 \% ;>64: 8 \%)$ and the life expectancy at birth is fairly high $(73 \mathrm{ys})$. The $1.3 \%$ rate of population increase for the region is in range with the world average. Countries with higher gross income per capita and higher levels of urbanisation like Uruguay, Argentina and Chile also have a correspondingly higher level of life expectation, a lower population growth and a lower proportion of population under 15 . On the other hand, countries with the lowest income per capita like Bolivia and Paraguay are the least urbanized, have the highest population annual growth and the lowest median age.

\section{EPIDEMIOLOGICAL ANALYSIS}

Core data on HIV/AIDS and tuberculosis rates and treatment are presented in Table $\mathbf{2}$.

\section{Epidemiology of HIV/AIDS}

The HIV/AIDS pandemic produced a significant impact in the region with an average prevalence of HIV infection above $0.5 \%$ in most of the countries included in the survey. The lowest burden $(<0.5 \%)$ is found in 3 Andean countries: Bolivia, Chile and Ecuador. Health care systems are in general well developed in the region and all countries run National AIDS Control Programmes (NACPs) with various degrees of data availability/reliability and programmatic efficiency. This diversity is clearly exposed by antiretroviral therapy (ART) coverage among people with advanced HIV infections, which is highest in Brazil (95\%), Argentina (71\%) and Chile (68\%) and lowest in Bolivia (18\%), Ecuador (24\%) and Paraguay (25\%). Information on HIV/AIDS epidemic and programme coverage in Chile, Ecuador and Venezuela is particularly poor. Scarce or null information is available on HIV/AIDS treatment success in most countries. Data on the impact of transmitted HIV drug resistance on the AIDS epidemic was made available only for Argentina (6\%) and Brazil (8\%).

\section{Epidemiology of TB}

TB burden is unevenly distributed in the region. Towards the end of the 20th century, the irruption of the HIV/AIDS pandemic arrested the slow but steady declining trend in TB incidence previously observed in the region. All countries run National TB Control Programmes (NTCPs) according to

Table 1. Demographic Profiles of 10 South American Countries, Adapted from the Statistical Information System of the World Health Organisation [4]

\begin{tabular}{|c|c|c|c|c|c|c|c|c|}
\hline & $\begin{array}{l}\text { Population } \\
\text { (Millions) }\end{array}$ & $\begin{array}{c}\text { Population Annual } \\
\text { Growth Rate (\%) }\end{array}$ & $\begin{array}{c}\text { Population in } \\
\text { Urban Areas (\%) }\end{array}$ & $\begin{array}{c}\text { Media Age } \\
\text { (Years) }\end{array}$ & $\begin{array}{l}\text { Life Expectancy } \\
\text { at Birth (Years) }\end{array}$ & $\begin{array}{c}\text { Population } \\
\text { Over } 60(\%)\end{array}$ & $\begin{array}{c}\text { Population } \\
\text { Under } 15 \text { (\%) }\end{array}$ & $\begin{array}{l}\text { Gross National } \\
\text { Income Per } \\
\text { Capita (U\$D) }\end{array}$ \\
\hline Bolivia & 9.5 & 1.9 & 65 & 21.9 & 66 & 5 & 36 & 3810 \\
\hline Brazil & 184.0 & 1.3 & 85 & 29.5 & 72 & 7 & 27 & 8700 \\
\hline Colombia & 44.5 & 1.4 & 73 & 26.5 & 74 & 6 & 29 & 6130 \\
\hline Ecuador & 13.3 & 1.1 & 63 & 25.4 & 73 & 7 & 31 & 6810 \\
\hline Paraguay & 6.3 & 1.9 & 59 & 25.7 & 75 & 5 & 34 & 4040 \\
\hline Peru & 28.8 & 1.1 & 73 & 28.4 & 73 & 6 & 31 & 6490 \\
\hline
\end{tabular}


Table 2. Basic Epidemiological Data on HIV and TB in 10 South American Countries

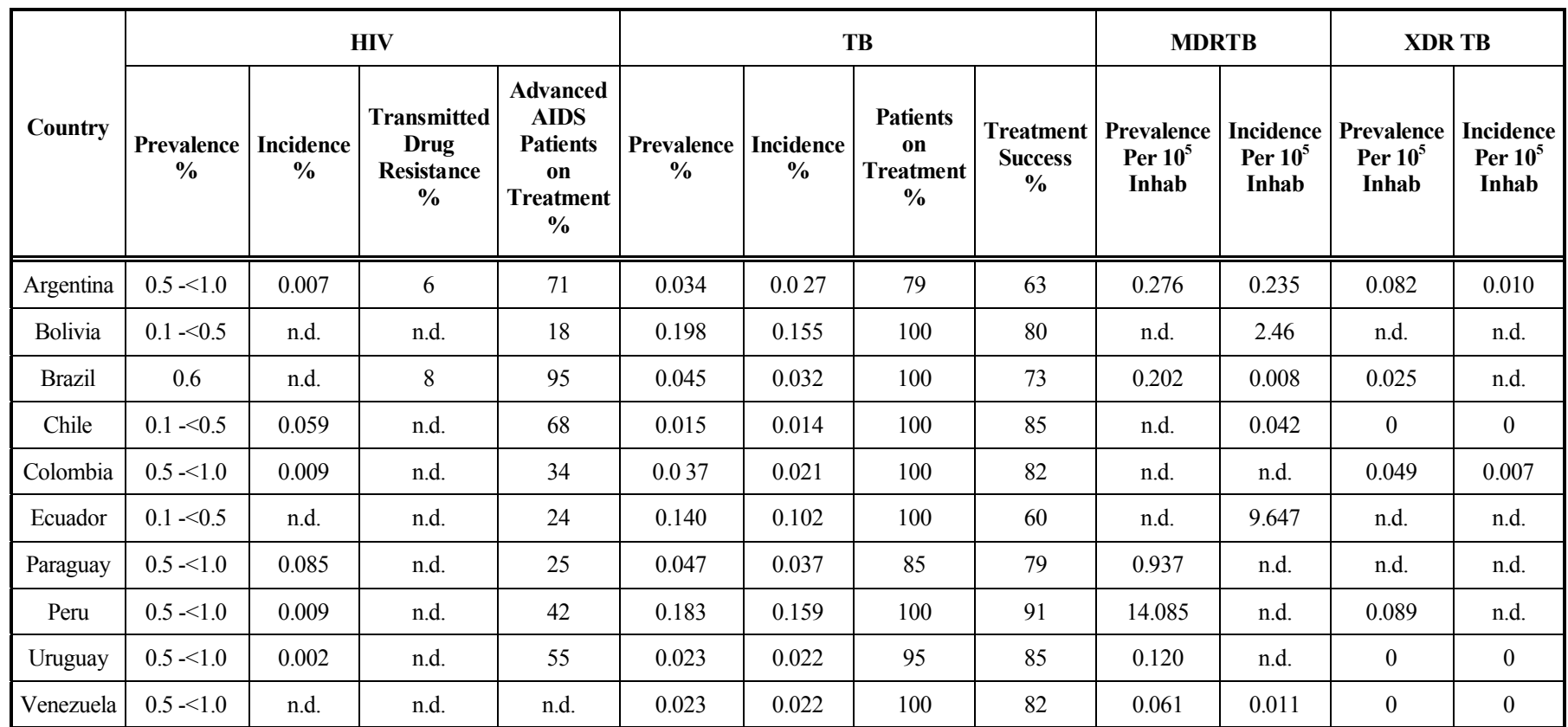

Sources: UNAIDS/WHO 2008 Report on the global AIDS epidemic [5], WHO Report on TB 2009 [6], WHO multidrug and extensively drug-resistant TB global report on surveillance and response [7] and official reports of national HIV/AIDS and national TB programmes.

HIV: human immunodeficiency virus; AIDS: acquired immunodeficiency syndrome; TB: tuberculosis; MDR: multidrug resistant; XDR: extensively drug resistant.

guidelines of the Pan American Health Organization (PAHO). Three Andean countries, namely Bolivia, Peru and Ecuador, bear the highest disease loads (198/100,000, $183 / 100,000$ and 140/100,000, respectively). The lowest rates are found in countries with long-dated, robust and disciplined NTCPs like Chile, Uruguay and Venezuela. Even in these latter countries, TB pockets or "hot spots" are found in vulnerable settings, including overpopulated urban areas, jails, across-border migrant communities and aboriginal communities. Across-border transmission of MTB follows the track of human migration from poorer countries like Bolivia, Peru and Paraguay to those which are more prosperous or provide better TB care like Chile, Argentina and Brazil.

In Uruguay, a long-dated and efficient NTCP database keeps an updated register and trace-back system in real time. Contact tracing is efficiently performed. Systematic interventions in state prisons for TB diagnosis, treatment and follow up have been recently incorporated. In sharp contrast, in Ecuador there is a big gap between TB officially-reported figures and WHO estimates, suggesting substantial TB underreporting.

MDR TB burden is very high in Peru and Ecuador and remains a problem in certain restricted areas of Argentina that underwent HIV-related MDR TB transmission in the nineties. On the other hand, rates of MDR TB are very low in Chile, Uruguay and Venezuela. Information from other countries is less reliable or insufficient. XDR TB cases have been reported in Peru (n: 70), Brazil (n: 47), Argentina (n: 33) and Colombia (n: 3). No XDR TB case has yet been detected in Uruguay, Chile and Venezuela.

\section{HIV/MTB Intersection}

In the South American countries included in the survey, prevalence of HIV infection in incident $\mathrm{TB}$ cases ranges between 3 and $15 \%$ and mortality attributable to HIV/MTB co-infection is lower than $1 / 100,000$.

Argentina counts with fairly strong HIV/AIDS and TB national programmes, highly trained health professionals and high quality laboratory diagnosis. The main weakness in fighting both diseases is related to decade-long socioeconomical decay and lack of involvement of successive government administrations. Various studies in Argentina coincide in reporting that people living with HIV account for around $8 \%$ of TB patients.

In Bolivia, the diagnosis and treatment coverage of both diseases is rather low. ART and second-line drugs for MDR TB treatment are not available in the country. Neither HIV/MTB co-infection or TB drug resistance is an important health threat. MTB co-migrates with human hosts across borders towards Northern Chile, Brazil and Argentina. The estimated prevalence of HIV infection in incident TB cases is estimated in 3\%.

In Brazil, $59.6 \%$ of patients with TB diagnosed in 2007 were tested for HIV, with seropositivity of $14.9 \%$. According to WHO estimates, that year occurred 11,632 TB cases in HIV infected people in Brazil although only 7,334 cases were reported to the country surveillance system. That year, 1,166 deaths were attributed to HIV/MTB co-infection [8].

In Chile there is a long-dated and robust NTCP but no explicit interaction between TB and HIV/AIDS control strategies. The information on HIV activities is scarce. The HIV/MTB co-infection (estimated from HIV prevalence in incident $\mathrm{TB}$ cases) is $4.7 \%$. MDR TB and HIV drug resistance do not pose severe problems.

In Colombia, the prevalence of MTB infection in the general population is estimated in $25 \%$ and the total number 
of people currently coinfected with MTB and HIV is estimated in 45,000 ( $25 \%$ of people living with HIV). In 2008, 440 prevalent TB cases and 358 new TB cases were reported in people living with HIV.

In Paraguay, the diagnosis and treatment coverage of both diseases, TB and AIDS, is low. ART and second-line drugs for treatment of MDR TB are not available in the country. Patients often seek health care in neighbouring countries, either as migrants or transient patient-visitors. MDR TB and HIV drug resistance as might not be a severe problem but information on the issue is not available. The prevalence of HIV infection in incident TB cases is $10-15 \%$.

Uruguay is a middle income country with a predominantly European rooted population, a very low population growth and a fairly even distribution of income. Both TB and HIV/AIDS programmes perform smoothly according to WHO standards and offer diagnosis and treatment free of charge. Consequently, rates of each disease and co-infection remain under control. Socioeconomic distress and HIV/AIDS epidemic emerging in the late '80s/early '90s hindered the previous trend towards TB elimination. HIV infection prevalence in incident TB cases is $10-15 \%$.

In Venezuela, 418 new cases of AIDS/TB were reported in 2007. Of all incident TB cases, $12 \%$ are estimated to be infected with HIV. No information is available on deaths attributable to AIDS/TB. Colombia and Peru are the usual sources of imported HIV and MTB infections.

\section{DIAGNOSIS}

\section{HIV/AIDS}

Country standards and availability of tests for HIV/AIDS diagnosis are presented in Table $\mathbf{3}$, as reported by the country experts. In all countries, ELISA tests are routinely conducted for HIV infection. If the first screening has a positive result, the sample is retested to confirm the result. CD4 counts by flow cytometry are available in most countries after HIV diagnosis to define patient's immune status. Viral load determination is used to test ART initiation and to monitor patients on treatment. Reportedly, phenotypic and/or genotypic HIV drug resistance testing is available in Argentina, Brazil, Chile, Colombia, Peru, Uruguay and Venezuela.

\section{Tuberculosis}

Country standards and availability of best possible tests for TB diagnosis are summarized in Table 4.

In all countries, NTCPs abide by standard TB diagnosis and treatment protocols following WHO/PAHO guidelines. According to such guidelines, primary TB diagnosis is largely based on sputum smear microscopy of symptomatic respiratory patients. MTB culture and drug susceptibility testing is only provided in particular cases, as defined in such guidelines. Therefore, diagnostic strategies vary amply, depending on patient age, disease localization and stage, comorbidity, risk of drug resistance, availability of tests, patient mobility, epidemiological environment, etc. Thus, overall diagnostic costs are highly variable. Only two countries, Chile and Uruguay, perform routinely MTB culture and drug susceptibility testing to all cases suspected of having TB.

Costs of TB diagnosis and treatment are covered by the public system. TB cases suspected at the private system level are usually referred to the public system for diagnosis and treatment.

\section{INTER-CULTURAL SENSITIVITIES}

Site specific policies, such as blood sample volumes, are not a major issue for clinical and scientific studies. Ethical

Table 3. Country Standards and Availability of Best Possible Tests for HIV/AIDS Diagnosis

\begin{tabular}{|c|c|c|c|c|c|c|c|c|c|}
\hline \multirow[b]{3}{*}{ Country } & \multicolumn{5}{|c|}{ Initial Diagnosis } & \multicolumn{2}{|c|}{ Follow Up } & \multicolumn{2}{|c|}{ Drug Resistance Testing } \\
\hline & Screening & Confirmation & CD4 & & ral Load & CD4 & Viral Load & Phenotypic & Genotyic* \\
\hline & $\begin{array}{c}\text { ELISA } \\
\text { Agglutination } \\
\text { Rapid Test }\end{array}$ & $\begin{array}{l}\text { Western } \\
\text { Blot IFA }\end{array}$ & $\begin{array}{c}\text { Flow } \\
\text { Cytometry }\end{array}$ & $\begin{array}{c}\text { RT-PCR } \\
\text { bDNA }\end{array}$ & $\begin{array}{l}\text { PCR as Primary } \\
\text { Diagnosis in } \\
\text { Children \& } \\
\text { Blood Donors }\end{array}$ & $\begin{array}{c}\text { Flow } \\
\text { Cytometry }\end{array}$ & $\begin{array}{c}\text { RT-PCR, } \\
\text { bDNA, } \\
\text { Taqman }\end{array}$ & $\begin{array}{c}\text { Virtual } \\
\text { Phenotype }\end{array}$ & $\begin{array}{c}\text { ViroSeq } \\
\text { Trugene }\end{array}$ \\
\hline Argentina & 1 & 1 & 4 & 4 & 2 & 1 & 1 & 2 & 2 \\
\hline Bolivia & 1 & 1 & n.d. & n.d. & n.d. & n.d. & n.d. & n.d. & n.d. \\
\hline Brazil & 1 & 1 & 2 & 1 & 2 & 1 & 2 & 3 & 2 \\
\hline Chile & 1 & 1 & 1 & 1 & n.d. & 1 & 1 & n.d. & 1 \\
\hline Colombia & 1 & 1 & 1 & 1 & n.d. & 1 & 1 & 4 & 3 \\
\hline Ecuador & 1 & 1 & n.d. & n.d. & n.d. & n.d. & n.d. & n.d. & n.d. \\
\hline Paraguay & 1 & 1 & n.d. & n.d. & n.d. & n.d. & n.d. & n.d. & n.d. \\
\hline Peru & 1 & 2 & 1 & 1 & n.d. & 1 & 1 & 4 & 2 \\
\hline Uruguay & 1 & 1 & 2 & 2 & n.d. & 2 & 2 & 4 & 3 \\
\hline Venezuela & 1 & 1 & 1 & 1 & n.d. & 1 & 1 & n.d. & 2 \\
\hline
\end{tabular}

HIV: human immunodeficiency virus; AIDS: acquired immunodeficiency syndrome; ELISA: enzyme-linked immunosorbent assay; IFA: immunofluorescence assay; RT-PCR: reverse transcription polymerase chain reaction assay; bDNA: branched chain DNA assay. 1: very common; 2: common; 3: rare; 4: not available; * for patients failing highly active antiretroviral therapy. 
Table 4. Country Standards and Availability of Best Possible Tests for TB Diagnosis

\begin{tabular}{|c|c|c|c|c|c|c|c|c|c|c|c|}
\hline \multirow{2}{*}{ Country } & \multicolumn{3}{|c|}{ Contact Tracing } & \multicolumn{9}{c|}{ Active TB Diagnosis } & \multicolumn{2}{c|}{ Drug Susceptibility Testing } \\
\cline { 2 - 14 } & Skin Test & X-Ray & IGRA & Skin Test & X-Ray & IGRA & Microscopy & Culture & PCR & Phenotypic & Genotypic* \\
\hline \hline Argentina & 1 & 2 & 4 & 2 & 1 & 4 & 1 & 2 & 3 & $2-3$ & $3-4$ \\
\hline Bolivia & 1 & 2 & 4 & 2 & 1 & 4 & 1 & 3 & 4 & 3 & 4. \\
\hline Brazil & 2 & 2 & 4 & 2 & 2 & 4 & 1 & 3 & 3 & $2-3$ & $3-4$ \\
\hline Chile & 1 & 2 & 4 & 2 & 1 & 4 & 1 & 2 & 4 & 1 & 4 \\
\hline Colombia & 3 & 4 & 3 & 3 & 1 & 4 & 1 & 2 & 4 & $2-3$ & 4 \\
\hline Ecuador & 1 & 2 & 4 & 2 & 1 & 4 & 1 & 2 & 4 & $2-3$ & 4 \\
\hline Paraguay & 1 & 2 & 4 & 2 & 1 & 4 & 1 & 3 & 4 & 3 & 4 \\
\hline Peru & 1 & 1 & 4 & $1-3$ & $1-3$ & 4 & 1 & 2 & 4 & 3 \\
\hline Uruguay & 1 & 2 & 4 & 1 & 1 & 4 & 1 & $1-2$ & 3 & 1 \\
\hline Venezuela & 1 & 1 & 4 & 1 & 1 & 4 & 1 & $1-2$ & 3 & $1-2$ & 4 \\
\hline
\end{tabular}

TB: tuberculosis; IGRA: interferon gamma release assay; PCR: polymerase chain reaction. 1: very common; 2: common; 3: rare; 4: not available; * for patients failing standard TB treatment or at risk of drug resistance.

approval is mandatory for local and international studies including human beings and biological samples. Ethical approval is also mandatory for new usage of biological samples.

Operational obstacles are frequently related with electric failure, transport delays, internet connectivity shortage, etc. The levels of such operational challenges vary from one country to another. Access to certain aboriginal communities may be prevented by geographical obstacles and language barriers in Andean and Amazonian areas.

There are no particular challenges related to deficiency in skills, including clinical, biotechnological and bioengineering expertise. An important deterring issue is related to bureaucratic mismanagement of human and financial resources. Procedures requiring government involvement are slow, inefficient and costly. Overall, there is insufficient political commitment to fight both diseases. The continuity of disease programmes and research activities are vulnerable to political and economical instability.

\section{BIOMEDICAL RESEARCH}

The following centres contribute substantially to biomedical research in the area of TB and/or HIV:

Fundação Oswaldo Cruz, FIOCRUZ, BRAZIL http:// www.fiocruz.br/

- Universidade Federal do Rio de Janeiro, BRAZIL http://www.ufrj.br/

- Instituto Adolfo Lutz, BRAZIL http://www.ial.sp. gov.br/

- Centro Nacional de Referencia para el Sida, CNRS, ARGENTINA http://www.cnrsida.org.ar/

- Administración Nacional de Laboratorios e Institutos de Salud, ANLIS, ARGENTINA http://www.anlis. gov.ar/

- Institute of Biotechnology, INTA, ARGENTINA www.inta.gov.ar/
- Universidad de Antioquia, COLOMBIA http://www. udea.edu.co/

- Corporación para Investigaciones Biológicas, CIB, COLOMBIA http://www.cib.org.co/web/

- CORPOGEN, COLOMBIA http://www.corpogen.org/

- Instituto Venezolano de Investigaciones Científicas, IVIC, VENEZUELA http:/www.ivic.gob.ve/

- Instituto Pasteur de Montevideo, URUGUAY http:// www.pasteur.edu.uy/

The most important funding programmes in the region are:

- $\quad$ CNPq BRAZIL www.cnpq.br

- $\quad$ STD/AIDS Program, Ministry of Health BRAZIL http://www.bnm.me.gov.ar/

- Colciencias COLOMBIA www.colciencias.gov.co

- $\quad$ Agencia (MinCyT) ARGENTINA www.agencia.min cyt.gov.ar

- CONICET www.conicet.gov.ar

- CABBIO, ARGENTINA-BRAZIL http://www.min cyt.gov.ar/cabbio2.htm

- AMSUD Pasteur www.amsudpasteur.edu.uy

- $\quad$ Cyted IBERO-AMERICA www.cyted.org

The most important ongoing projects are:

At the national level:

- $\quad$ RedeTB, BRAZIL http://redetb.org.br

- Colombian Centre of Excellence for TB research, COLOMBIA

- The Peruvian experience on TB \& HIV harmonization, PERU

PAE research for TB control, ARGENTINA www. tuberculosiscontrol.org.ar 
At the regional level:

\section{- $\quad$ CNPq on TB research LATIN AMERICA}

- MULTITUB on MDR TB transmission surveillance, Cyted IBERO-AMERICA

- Natural anti-TB drug discovery, Cyted IBEROAMERICA

All 10 countries in the region are involved, to different extents, in biomedical research on HIV/AIDS and TB. Brazil is largely the major scientific contributor as shown by the number of PubMed indexed publications on these issues [9]. The earliest Brazilian paper on AIDS was published as early as 1985. Still, the research specifically addressing the interaction between both infections is remarkably scarce and represents less than $10 \%$ of the whole set (Table 5).

Table 5. Scientific Publications on HIV/AIDS, TB, and HIV/AIDS and TB Association

\begin{tabular}{|c|c|c|c|c|c|}
\hline \multirow{2}{*}{ Country } & \multicolumn{5}{|c|}{ Number of Papers* } \\
\cline { 2 - 6 } & HIV & AIDS & HIV \& TB & AIDS \& TB & TB \\
\hline \hline Argentina & 604 & 451 & 66 & 46 & 372 \\
\hline Bolivia & 30 & 24 & 4 & 3 & 46 \\
\hline Brazil & 2603 & 2123 & 224 & 209 & 1194 \\
\hline Chile & 177 & 186 & 21 & 17 & 167 \\
\hline Colombia & 175 & 132 & 16 & 15 & 173 \\
\hline Ecuador & 42 & 30 & 3 & 2 & 41 \\
\hline Paraguay & 32 & 17 & 3 & 2 & 20 \\
\hline Peru & 223 & 157 & 36 & 21 & 226 \\
\hline Uruguay & 46 & 29 & 5 & 3 & 63 \\
\hline Venezuela & 138 & 105 & 9 & 10 & 115 \\
\hline
\end{tabular}

HIV: human immunodeficiency virus; AIDS: acquired immunodeficiency syndrome; TB: tuberculosis.

*As retreived from PubMed according to the countries and the targeted key words (Search performed on 17 July 2009).

\section{REMARKS}

\section{Facts in General}

- The HIV pandemic has hindered the previous slow, but steady, TB decline in the region, even in countries running long-dated TB programmes with excellent performance like Uruguay and Chile.

- All countries in the region adhere to common diagnostic and treatment standards for $\mathrm{TB}$ and HIV/AIDS according to WHO/PAHO guidelines. Diagnosis and treatment are free of charge in the whole region.

- The main weaknesses are related to insufficient involvement of government administrations, to poverty-related pockets of HIV/MTB co-infection in urban/suburban settings and to lack of interaction between HIV/AIDS and TB programmatic interventions.
- TB diagnosis relies widely in AFB smear microscopy, a method with very low sensitivity, particularly in persons living with HIV.

- Quality of information and intervention coverage are suboptimal and uneven between countries.

- $\quad$ Biomedical research and interventions on HIV/AIDS and TB are partially supported by international funds/loans. Funds for HIV/AIDS are disproportionally higher than those allocated to $\mathrm{TB}$ and there is hardly any investment in the dual infection.

\section{Facts in Particular}

- $\quad$ AIDS-related MDR TB, and lately XDR TB, emerged as a serious problem in some countries, namely Argentina, Brazil, Peru and Ecuador, especially in overpopulated urban areas. This denotes a failure in TB control interventions, particularly, in hospital infection control.

- Across-border transmission of $\mathrm{TB}$ is driven by migrants from countries with less robust programmes and/or higher disease burden (Bolivia, Paraguay, Peru) to countries where diagnosis and treatment are more widely available (Argentina, Brazil, Chile). Venezuela receives TB immigrants from Colombia, Peru and Ecuador. There is no accurate estimate of the impact of migration on the regional epidemic of the dual infection.

- With the exception of Uruguay, TB/AIDS in jails has not been effectively addressed by national programmes.

- $\quad$ Policies implemented in Brazil for local development of generic drugs have hardly reduced the price of HIV/AIDS treatment. Lack of local investments in pharmochemical research and development are huge obstacles to reduce the dependence on imported drug.

\section{Institutional and Operational Breaches}

- Inaccurate data on burden and impact of TB on people living with HIV

- Insufficient access of people living with HIV to TB screening and treatment

- $\quad$ Long time to TB diagnosis

- $\quad$ Emergence of MTB drug resistance

- Insufficient information on HIV drug resistance and its impact on treatment efficacy

- Insufficient or null synergism between TB and HIV/AIDS programatic interventions and research

- Limitations in local funds for research: constrained budgets and short cycles of funding, specially for clinical research and no funds for cohort studies

- Operational delays/fund constraints to run competitive scientific projects 


\section{Scientific Challenges}

\section{Therapy and Drug Interactions}

- $\quad$ Role of isoniazid preventive therapy in adults and children with access to ART

- $\quad$ Optimal time of initiating ART in people living with HIV/AIDS who have TB

- Adverse interactions between anti-TB and anti-HIV drugs

- $\quad$ Drug development, including innovative approaches to drug discovery

- Participation in the international effort for the development and testing of vaccines for HIV and MTB

\section{Diagnostics}

- Development of sensitive and affordable point of care TB diagnostic methods for people living with HIV and HIV diagnostic methods for TB patients, particularly in children and smear negative adult TB patients

- $\quad$ Rapid/affordable methods for detection of HIV drug resistance, MDR and XDR MTB

- Predictive value of IGRAs for latent MTB infection/progression to active TB disease in people living with HIV

- Studies on efficiency and cost-effectiveness of new tools

- Molecular epidemiology of MDR/XDR MTB and drug resistant HIV, with emphasis in particular settings (hospitals, jails, mental institutions, homeless shelters) and vulnerable populations (pregnant women, recent HIV seroconverters, homeless, indigenous populations, across-border migrants).

\section{Translational Research}

- Molecular basis of HIV and MTB drug resistance

- Phylogeography of HIV and MTB in relation to fitness and drug resistance

- Understanding Immune Reconstitution Syndrome (IRIS)

- Immunological basis of HIV and MTB reinfection and superinfection

\section{CONCLUSIONS}

As it happens in many other regions in the world, in South American countries HIV/AIDS and TB programmatic actions are seldom coordinated and there is a lack of health personnel trained to manage both diseases [10]. The funds allotted to TB management and research are disproportionally lower than those destined to HIV/AIDS [11]. To counteract the biological synergy HIV/MTB, vigorous coordinated health interventions are required as well as the fostering of biomedical research focused on the dual epidemic at the national and regional level [12].

\section{ACKNOWLEDGEMENTS}

The work presented in this manuscript is derived from the EUCO-Net project funded by the 7th Framework Programme of the European Commission. The following country experts assisted to the authors in compiling the information: Maria Alejandra Alvarez and Horacio Salomon (Argentina), Valdilea Veloso, Afranio Kritski and Francisco Inácio Bastos (Brazil), María Teresa Rugeles, María Patricia Arbelaez, Carlos Rojas, Luis F. Barrera and Lucelly López (Colombia), Cesar Bonilla Asalde and Juan Carlos Hurtado (Peru), María Luz Osimani and Jorge Rodríguez-De Marco (Uruguay), Mercedes España (Venezuela).

\section{ABBREVIATIONS}

$\begin{array}{ll}\text { AIDS } & =\text { Acquired immunodeficiency syndrome } \\ \text { ART } & =\text { Antiretroviral therapy } \\ \text { DOTS } & =\text { Directly observed therapy-short course } \\ \text { EUCO-Net } & =\text { Network of European/ICPC cooperation in } \\ & \text { the field of AIDS and TB } \\ \text { HIV } & =\text { Human immunodeficiency virus } \\ \text { IPT } & =\text { Isoniazid preventive therapy } \\ \text { IGRAs } & =\text { Interferon gamma release assays (blood tests } \\ & \text { aimed to determine whether a person has } \\ \text { IRIS } & =\text { Immune reconstitution inflammatory } \\ & \text { syndrome } \\ \text { LA } & =\text { Latin America } \\ \text { MDR } & =\text { Multidrug resistant } \\ \text { MTB } & =\text { Mycobacterium tuberculosis } \\ \text { NACP } & =\text { National AIDS Control Programme } \\ \text { NHLS } & =\text { National Health Laboratory Service } \\ \text { NTCP } & =\text { National TB Control Programme } \\ \text { PAHO } & =\text { Pan American Health Organization } \\ \text { TB } & =\text { Tuberculosis } \\ \text { HIV/MTB }= & \text { The intersecting epidemics of MTB and } \\ \text { TBPT } & =\text { HIV } \\ \text { WHO } & =\text { World Health Organization } \\ \text { XDR } & =\text { Extensively drug resistant }\end{array}$

\section{REFERENCES}

[1] Mayer KH, Dukes Hamilton C. Synergistic pandemics: confronting the global HIV and tuberculosis epidemics. Clin Infect Dis 2010; 50 (Suppl 3): S67-70.

[2] Lawn SD, Churchyard G. Epidemiology of HIV-associated tuberculosis. Curr Opin HIV AIDS 2009; 4: 325-33.

[3] Getahun H, Havlir D, Granich R, Reid A, Jaramillo E, Nunn P. Paradigm shift to address drug resistant tuberculosis in people living with HIV needed, and needed now. Trop Med Int Health 2009; 14 : 376-8.

[4] WHO Statistical Information System (WHOSIS) http://www.who. int/whosis/en/ [Accessed: October 2010].

[5] UNAIDS/WHO: 2008 Report on the global AIDS epidemic. 2008 http://www.unaids.org/en/KnowledgeCentre/HIVData/GlobalRepor t/2008/2008_Global_report.asp [Accessed: October 2010]. 
[6] WHO TB report. HIV-related TB deaths higher than past estimates 2009. http://www.who.int/mediacentre/news/releases/2009/tubercu losis_report_20090324/en/index.html/[Accessed: October 2010].

[7] WHO . Multidrug and extensively drug-resistant TB global report on surveillance and response. WHO/HTM/TB/2010.3, 2010.

[8] Wendel SN, Russo C, Bertoni RR, Tsunoda NM, Ghaname JN. AIDS and blood donors in Brazil. Lancet 1985; 2(8453): 506.

[9] Kritski AL, Villa TS, Trajman A, Lapa E Silva JR, Medronho RA, Ruffino-Netto A. Two decades of research on tuberculosis in Brazil: state of the art of scientific publications. Rev Saude Publica 2008; 41 (Suppl 1): 9-14.
[10] Ramon-Pardo P, Jacquet V, Armengol R, Montero C, Echegaray C, Del Granado MV. Scaling up collaborative TB-HIV activities in Latin America. Int J Tuberc Lung Dis 2008; 12:S51-S3.

[11] Harrington M. From HIV to tuberculosis and back again: a tale of activism in 2 pandemics. Clin Infect Dis 2010; 50 (Suppl 3): S2606.

[12] Smart T. Catalysing HIV/TB research: a meeting report. HIV \& TB treatment in practice. 147, $2009 \mathrm{http}: / /$ www.stoptb.org/wg/tb_hiv/ meetings_2009.asp [Accessed: October 2010].

(C) Ritacco et al.; Licensee Bentham Open.

This is an open access article licensed under the terms of the Creative Commons Attribution Non-Commercial License (http://creativecommons.org/licenses/ by-nc/3.0/) which permits unrestricted, non-commercial use, distribution and reproduction in any medium, provided the work is properly cited. 